$\begin{array}{cc}\text { ACADEMIA ROMÂNĂ } & \text { Rev. Roum. Chim., } \\ \text { 2020 65(4), 329-341 } & \text { DOI: 10.33224/rrch.2020.65.4.02 } \\ \text { Revue Roumaine de Chimie } & \text { http://web.icf.ro/rrch/ }\end{array}$

Papers

\title{
INJECTION MOLDED PART MATERIAL FAILURE ANALYSIS
}

\author{
Nicolae SOLOMON ${ }^{\mathrm{a},{ }^{*}}$ and Iulia SOLOMON ${ }^{\mathrm{b}}$ \\ a "Stefan cel Mare" Suceava University, Str. Universitatii nr.13, 720229 Suceava, Roumania \\ b "Dunarea de Jos" Galati University, Str. Domneasca nr.47, 6200 Galati, Roumania
}

Received August 17, 2019

\begin{abstract}
In this study, the causes of the failure of an injection-molded polyamide part were analyzed. The working conditions of injection-molded parts are very complex depending on: pressure, temperature, friction, corrosion, etc. and, consequently, they could fail due to different reasons. Microscopic characterization, thermogravimetric analysis (TGA), differential scanning calorimetry (DSC) and FTIR spectroscopy were used for fracture analysis of defected parts. Mechanical testing (flexural modulus, torque and notched Izod impact test) was also considered for part failure analysis. This analysis suggests that the parts have failed because they were overloaded during assembly operation, and their material was harder (in a transition state between ductile and brittle) than the parts from normal production (in ductile state). Our investigations revealed that, due to plastic deformation at room temperature, Nylon 6 presents an

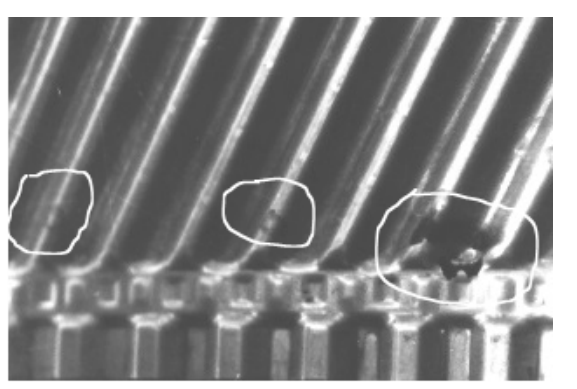
unusual phase transformation. There are similarities between austenitic stainless steel and Nylon 6 . Thus, it consists in the fact that their $\gamma$ forms transform into $\alpha$ forms, due to an applied heat treatment or at room temperature as a result of an applied pressure (plastic deformation). In both situations, material became harder and then less resistant to applied physico-mechanical actions. In this particular case, an unusual local material hardening was observed due to a combined influence of two processes (cooling process, torque test), with a failure of the molded parts.
\end{abstract}

\section{INTRODUCTION}

In recent decades, plastic molding of polymeric materials is the most frequently used method for manufacturing automotive parts for exterior side of a car like: bumpers, headlight housings, side mirror housings, front grille, wheel covers, panoramic roof, etc., as well as for interior side, such as door panels, center console and instrument panel. Regarding the technologies used to manufacture the polymeric materials as automotive components, extrusion, blow molding, injection molding, compression molding, thermoforming, vacuum forming, etc., could be mentioned as the most used molding processes. The working conditions of injection-molded parts (pressure, temperature, friction and corrosion, etc.) generally may lead to material failure in different manners. The sensitivity of polymeric materials to processing and environmental conditions is much greater than for traditional engineering materials. Plastic parts could exhibit different kinds of failures such as fatigue, molecular degradation/oxidation, brittle fracture and environmental stress cracking. Plastic parts have the ability to be pressed or snap fit which is not possible with metals, but it is important to consider compression and toughness or creep characteristics to ensure product performances. Mechanical failure of polymeric materials arises from the applied external forces which, when exceeded the yield strength of the material, could cause the product to deform, crack

\footnotetext{
${ }^{*}$ Corresponding author: e-mail: nsolomon@fia.usv.ro
} 
or break into pieces. According to Pala et al., ${ }^{1}$ temperature has important effects on deformation phenomena Microstructural defect rearrangement processes are often accelerated at high temperatures. The prediction of strength and impact resistance of plastic parts is probably the most difficult challenge for the design engineer. Tensile stress-strain measurements as a function of temperature and strain rate provide very useful information. ${ }^{2-4}$

Structural faults, thermal stress, lack of mechanical resistance, environmental stress, working temperature above tempering (which could lead to the phase transition) could be considered the main reasons for fracture and deformation failure of molded parts. ${ }^{5-7}$

Nikforooz et al. ${ }^{8}$ have studied fatigue behavior of laminated glass fiber-reinforced polyamide. In contrast to the behavior of unidirectional laminates, glass/polyamide laminates had a superior fatigue resistance compared to the glass/epoxy composite. This behavior was explained by the higher toughness of glass/polyamide laminates which decreases the stiffness degradation caused by the transverse matrix cracking. The influence of processing-induced crystalline orientation on the macroscopic deformation was also studied. ${ }^{9}$ A lamellar structure oriented perpendicular to loading direction leads to an increase in strain hardening.

Zhou and Mallick ${ }^{10}$ have analyzed the effects of specimen orientation with respect to the flow direction, hole stress concentration and weld line on the fatigue life of a component. The material modulus, tensile strength and the fatigue strength were found to be significantly higher in the flow direction than normal one, which indicates an inherent anisotropy of the material caused by flowinduced orientation of fibers.

Even though plastic materials are inherently ductile, they fail in a brittle manner. Preventing the fracture failure of the injection-molded parts is one of the most important preoccupation of engineering specialists. Understanding the actual reason for failures is absolutely required to avoid recurrence and prevent failure in similar components, systems, structures or products.

In many situations, manufacturing process itself is crucial when it comes to preventing plastic failure. Often moisture in the material, weak welding or molded-in stress can result in a dramatically weakened product, shortening the projected lifespan of the work piece.
Failure analysis is used for identifying and understanding the physics of the failure processes and mechanisms. There are several methods that can be used to find out the real causes of a failed part. Cause and effect diagram, one of the most used techniques for failure analysis, indicates how equipment, process, people, materials, environment and management contributed to a component failure. The purpose of this paper is to identify the causes of the fracture failure of an injectionmolded polyamide part.

\section{Case Study}

At first, we investigated a defective molded polyamide clamshell part, used in automotive industry to determine the reason for crack failure (Figure 1). It was reported that the crack failure had developed while the molded part was merged to the mounting pin (Figure 2). Reference material was provided to run comparative analysis. According to the customer statement, some molded parts were found to be warped, difficult to install them onto assembly: "several clamshell parts could not be assembled in the accumulator assembly because they were not flat." Afterward, other 2 defected molded parts and resin beads of Nylon 6 were sent for fracture failure analysis. Nylon 6 (PA6) main characteristics are presented in Table 1. The suspect production began failing with 2 parts/shift and reached a peak of an average 1 failure per hour and during a week a total of 88 broken brackets, before the process to be stabilized.

\section{Molding Process Analysis}

The suspect parts were molded on a horizontal molding machine with the following characteristics: machine size -650 tons; unit type: hot runner $288^{\circ} \mathrm{C}\left( \pm 6.67{ }^{\circ} \mathrm{C}\right)$; nozzle orifice $-6.35 \mathrm{~mm}$; cycle time: $74.00 \mathrm{~s}$.; cooling time: $28.00 \mathrm{~s}$. The polymer material used for parts manufacture was Nylon 6 (PA6) with the following prescribed injection molding parameters: material type -PA6; melt temperature $220-280{ }^{\circ} \mathrm{C}$; injection speed - high; injection pressure $\mathrm{MPa}$ 75-125 $\mathrm{MPa}$; mold temperature $70-90{ }^{\circ} \mathrm{C}$; drying conditions: drying in a hot air oven at $80{ }^{\circ} \mathrm{C}$ for 16 hours is recommended. If the material has been exposed to air for more than $8 \mathrm{~h}$, vacuum drying at $105^{\circ} \mathrm{C}$ for more than $8 \mathrm{~h}$ is recommended. 


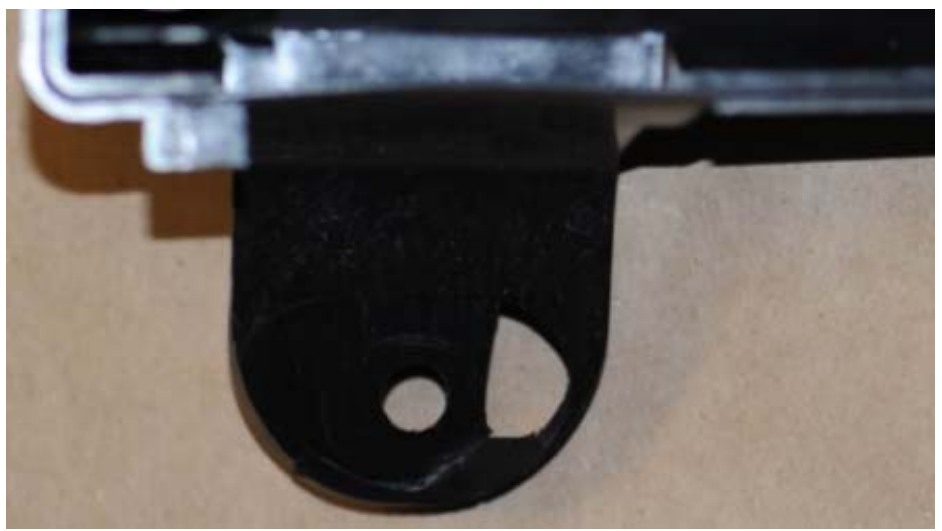

Fig. 1 - Defective part because of crack failure.

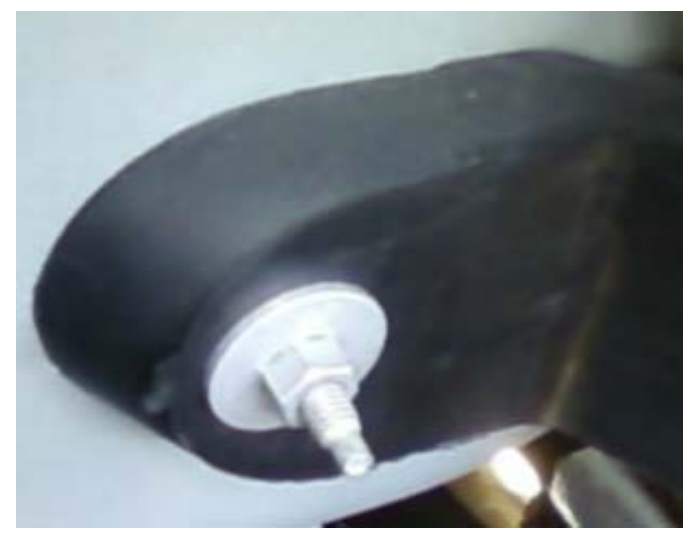

Fig. 2 - Bracket - pin assembly.

Table 1

Nylon 6-PA6 - datasheet

\begin{tabular}{l|c|c|l}
\hline Processing/Physical Characteristics & Value & Unit & Test Standard \\
\hline ISO Data & & & \\
\hline Molding shrinkage, parallel & 1.5 & $\%$ & ISO 294-4, 2577 \\
Thermal conductivity of melt & 0.23 & $\mathrm{~W} /(\mathrm{m} \mathrm{K})$ & ISO 22007-2:2017; DIN 52612 \\
\hline Mechanical properties & Value & Unit & Test Standard \\
\hline ISO Data & & & \\
\hline Tensile Modulus & 2700 & $\mathrm{MPa}$ & ISO 527 \\
Yield stress & 70 & $\mathrm{MPa}$ & ISO 527 \\
Strain at break & 15 & $\%$ & ISO 527 \\
Charpy impact strength, $+23^{\circ} \mathrm{C}$ & $\mathrm{N}$ & $\mathrm{kJ} / \mathrm{m}^{2}$ & ISO $179 / 1 \mathrm{eU}$ \\
Charpy notched impact strength, $+23^{\circ} \mathrm{C}$ & 8.5 & $\mathrm{~kJ} / \mathrm{m}^{2}$ & ISO $179 / 1 \mathrm{eA}$ \\
\hline Thermal properties & Value & Unit & Test Standard \\
\hline ISO Data & & & \\
\hline Melting temperature, $10^{\circ} \mathrm{C} / \mathrm{min}$ & 221 & ${ }^{\circ} \mathrm{C}$ & ISO $11357-1 /-3$ \\
Temp. of deflection under load, $0.45 \mathrm{MPa}$ & 185 & ${ }^{\circ} \mathrm{C}$ & ISO $75-1 /-2$ \\
\hline Other properties & Value & Unit & Test Standard \\
\hline Humidity absorption & 2.2 & $\%$ & Sim. to ISO 62 \\
Density & $1.10010^{3}$ & $\mathrm{Kg} / \mathrm{m}^{3}$ & ISO 1183 \\
\hline
\end{tabular}

When the warpage issue was reported, the mold was found to run, hotter with approximately $15^{\circ}$ $25^{\circ}$, in one area than in the others. It happened because the cooling system was found to be partially clogged. It was hot enough to cause part warpage and a slight material degradation.
Consequently, several parts were found to be harder (in a transition state between ductile and brittle) than the ones from normal production (in ductile state). This is why more than 30 pieces failed for a torque above $3.0 \mathrm{Nm}$, when they were installed on the pin of assembly. 


\section{EXPERIMENTAL}

Depending on the nature of a failure, several stages of investigations were followed. Generally, a failure analysis consists of two stages: preliminary and final. During preliminary stage, it is compulsory to collect information about the samples to be investigated, to make a visual inspection of the failed part(s) and, if necessary, a nondestructive testing. In the case of a fracture analysis, the final stage of an investigation consists of the following steps:

Evaluation of the damages and conditions which led the part to failure. Fish bone diagram, a useful quality tool, can be used for this evaluation. It helps to find out which factors contributed the most to the part(s) failure. These factors could be related to: operators, machines, materials, methods, measurements or to the environment;

Macroscopic examination and microscopic examination of fractured samples;

Chemical analysis;

Stress and stain analysis;

Fracture appearance and mechanisms;

Results interpretation.

To the aforementioned steps of an investigation, other additional steps could be added. They must be correlated with the working conditions where the part failure took place.

\section{RESULTS AND DISCUSSION}

The primary objective of a materials failure analysis is to determine the root cause of failure. Whether dealing with metallic or nonmetallic materials, the root cause can normally be assigned to one of the following four categories: design, manufacturing, service and material. Many of the techniques utilized over the years for the evaluation of metals have been successfully applied to plastics with only minor modifications. The defective product returned from customer/end user is often subjected to a variety of mechanical and or physical tests to determine integrity of the product. ${ }^{11}$

\section{Failure Analysis - Macroscopic Examination and Microscopic Examination}

The macroscopic examination brings information about location of fracture and origin, direction of cracking, configuration of the stress state and the last region to fail. The broken parts were inspected visually and by stereoscope at magnifications of 6.7 to $45 \mathrm{X}$ to determine the cause of failure. One of the received samples for fracture failure analysis is shown in Figure 3. It presents fractures along one of its legs. It was noted that a section of the fractured leg was missing and a circular indentation on the exterior surface of the leg was also visible (Figure 3 ). It can be also seen that the washer indentation was on the entire leg surface. It shows that the pin of the assembled part was not centered to the hole, when it was installed on the bracket. Further examination of the sample disclosed the presence of what appeared to be a flow pattern along the exterior surface of the legs. The typical appearance of this condition is shown in Figure 4. Visual examination of the bracket fractured surfaces revealed a faceted fracture surface, with no significant whitish discoloration or deformation, which is consistent with a brittle material overload. Additionally, the presence of a mirror zone and rib marks were also detected. The mirror zones are flat, featureless regions that surround the fracture origin in plastic failures. It was noted that the mirror zone appears to be primarily along the exterior surface. Microscopic examination of the fractured region disclosed the presence of secondary cracks connected to the main fracture. This feature is shown in Figure 5. The map of the fracture indicates a relative material ductility, as a function of temperature and strain rate, for a relatively severe stress state $[12,13]$. A cross section (perpendicular to the observed flow lines) was removed and polished for examination. Thus, microscopic examination showed that the flow lines appeared to be relatively shallow and did not penetrate deep into the cross section. This aspect is shown in Figure 6. All cracks appear to be initiated from the washer indentation of the mating pin, which was installed on molded polyamide clamshell part, and propagated outward. The fracture of the broken area exhibits a grainy, irregular tarring texture. The broken area (Figures 1 and 3) presents characteristics of a brittle fracture, which has a little or no plastic deformation prior to fail. Due to molecular degradation during molding process, the material of the part was significantly embrittled because of molecular degradation, and consequently, a brittle fracture occurred during pin assembly. Specimens from broken part, resin beads and from a good-quality molded part were analyzed using FTIR spectroscopy. 


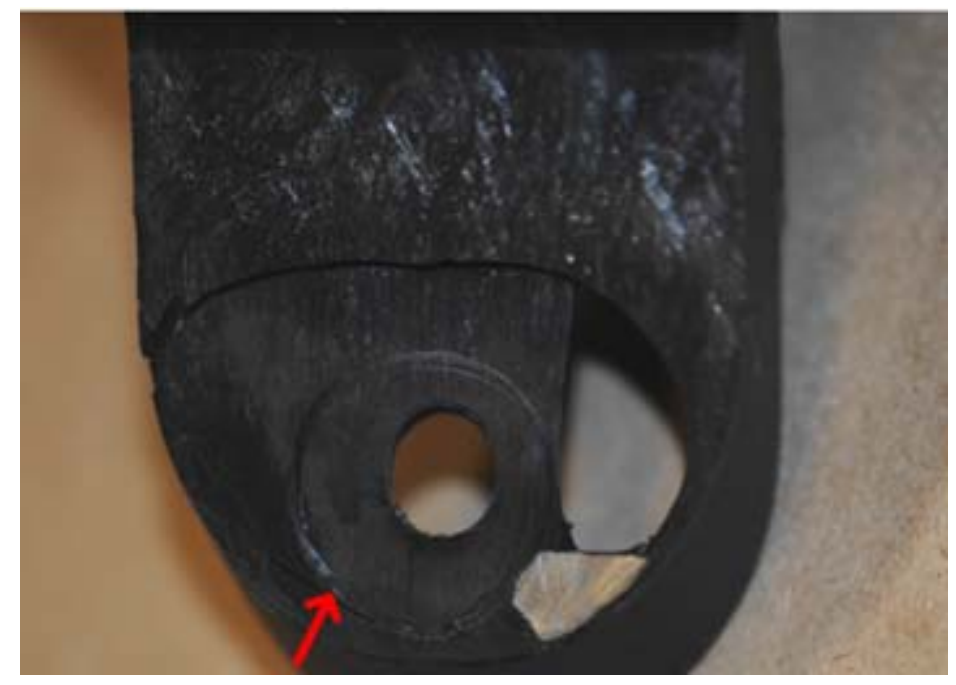

Fig. 3 - Defective part - circular indentation (severe tool marks).

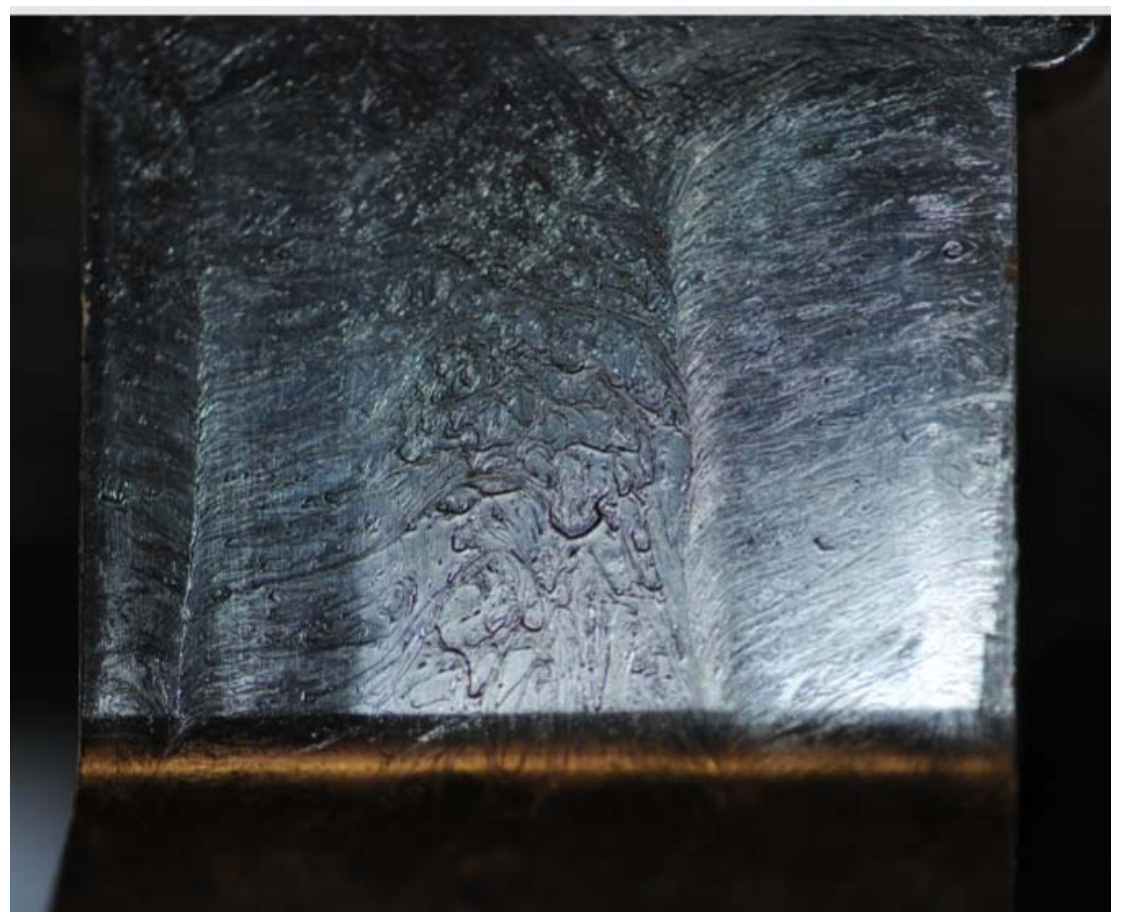

Fig. 4 - Flow pattern along the exterior surface of the leg.

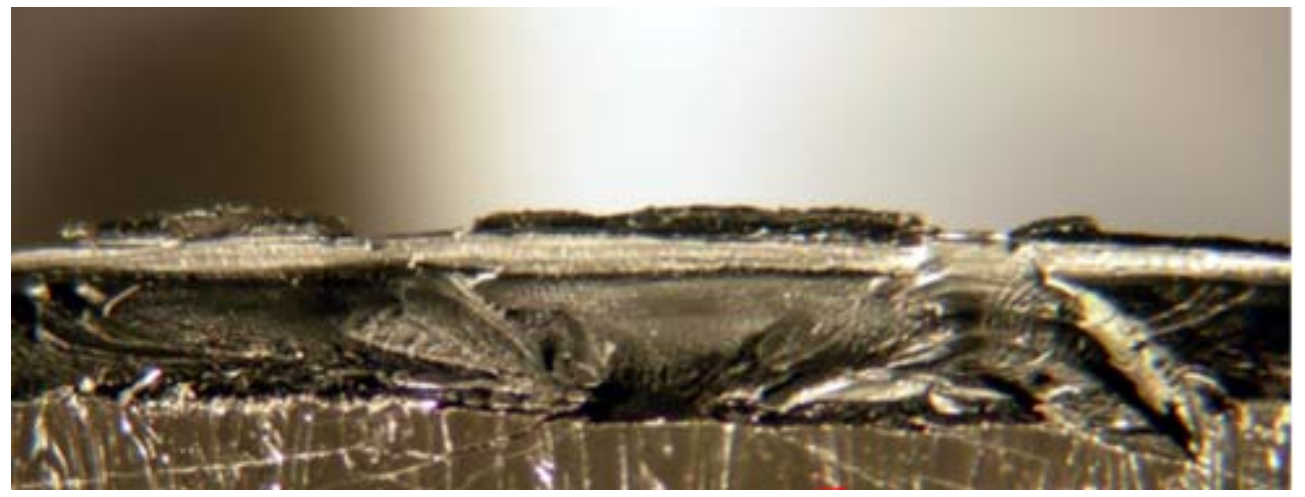

Fig. 5 - Secondary cracks connected to the main fracture. 


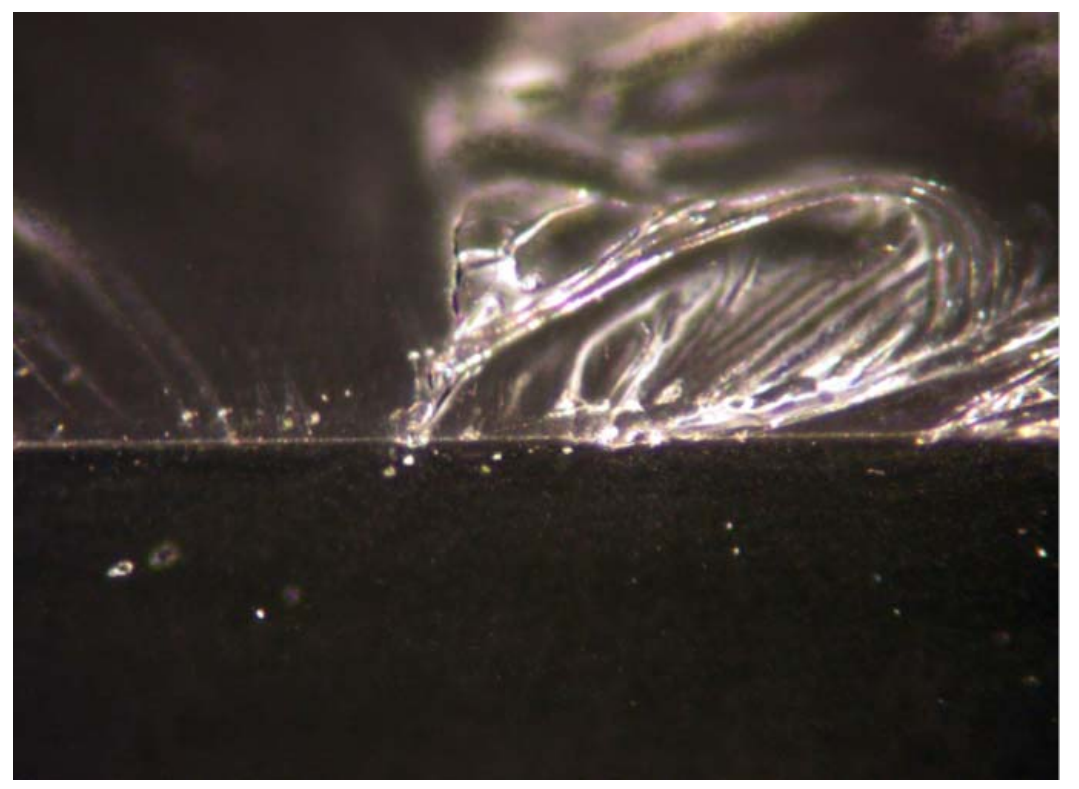

Fig. 6 - Cross section - flow lines.

\section{Fourier Transform Infrared Spectroscopy}

In the case of any failure analysis, it is mandatory to prove that the failed part(s) was made from the same raw materials in accordance to the good quality specifications of the product, similar to Nylon 6, as shown in Figure 7. The presence of contaminant materials, additives and filler materials within submitted samples was not detected. However, the resulting data indicate that the analyzed broken part presents an increase of crystallization. As aforementioned, the fracture surface of failed molded part shows only brittle features. According to the manufacturer information, one zone of the mold of these parts was running hotter than in normal conditions with approximately $15^{\circ}-25^{\circ} \mathrm{C}$, because the cooling system was found to be partially blocked. It is known that a high molding temperature accelerates material brittleness. Consistent with literature data, ${ }^{14-22}$ Nylon 6 presents three crystalline phases: $\alpha, \gamma$ and $\beta$ (a mixture of both phases $\alpha$ and $\gamma$ ), depending on the crystallization conditions. Usually, Nylon 6 crystallizes in both phases, $\alpha$ and $\gamma$. In FTIR spectra of black resin, the absorption bands at 930, 1124, 1170, 1202 and $1274 \mathrm{~cm}^{-1}$ are attributed to the $\alpha$-crystalline phase. In the case of the failed part, the new absorption bands on the FTIR infragraph at 977 and $1081 \mathrm{~cm}^{-1}$ are assigned to the $\gamma$ crystalline phase. A material with greater crystallinity is always accompanied by a reduction in impact resistance. It is well known that the $\gamma$ crystallization can occur only from the amorphous phase. ${ }^{16}$ In the case of Nylon 6 , the $\gamma$ phase is less stable and it can be easily transformed to $\alpha$ phase, through various treatments (e.g., recrystallization, annealing at $160^{\circ} \mathrm{C}$ in a saturated-steam atmosphere) including pressure at room temperature. ${ }^{14,23-28}$ It is a similar phenomenon to austenite $(\gamma)$ transformation into martensite $(\alpha)$ due to cold plastic deformation, which takes place in the case of austenitic stainless steel. ${ }^{5}$ In both circumstances, $\gamma$ form converts into $\alpha$ form, and then, this transformation is followed by material hardening, which leads eventually to material failure. However, it does not mean that $\alpha$ and $\gamma$ phases of Nylon 6 are similar to the ones of the aforementioned stainless steel. In the case of Nylon 6 , the main difference between these two phases $\alpha$ and $\gamma$ consists of orientation of the plane of the amide group and that of the $\left(\mathrm{CH}_{2}\right)_{5}$ group, which are parallel in the case of $\alpha$ form, while in the $\gamma$ form they are almost perpendicularly oriented. ${ }^{24}$

In addition to the absorption bands at 977 and $1274 \mathrm{~cm}^{-1}$, the spectra obtained on the failed parts show a vibration band at approximately $1740 \mathrm{~cm}^{-1}$ which indicates a partial oxidative degradation of the resin. The oxidation/degradation phase can be the cause of part shrinkage, which generates internal tensile stress with direct consequences in the occurrence of microcracks and, eventually, of part failure. As the analyzed part has never been in service, the aforementioned material degradation took place only during molding process. 


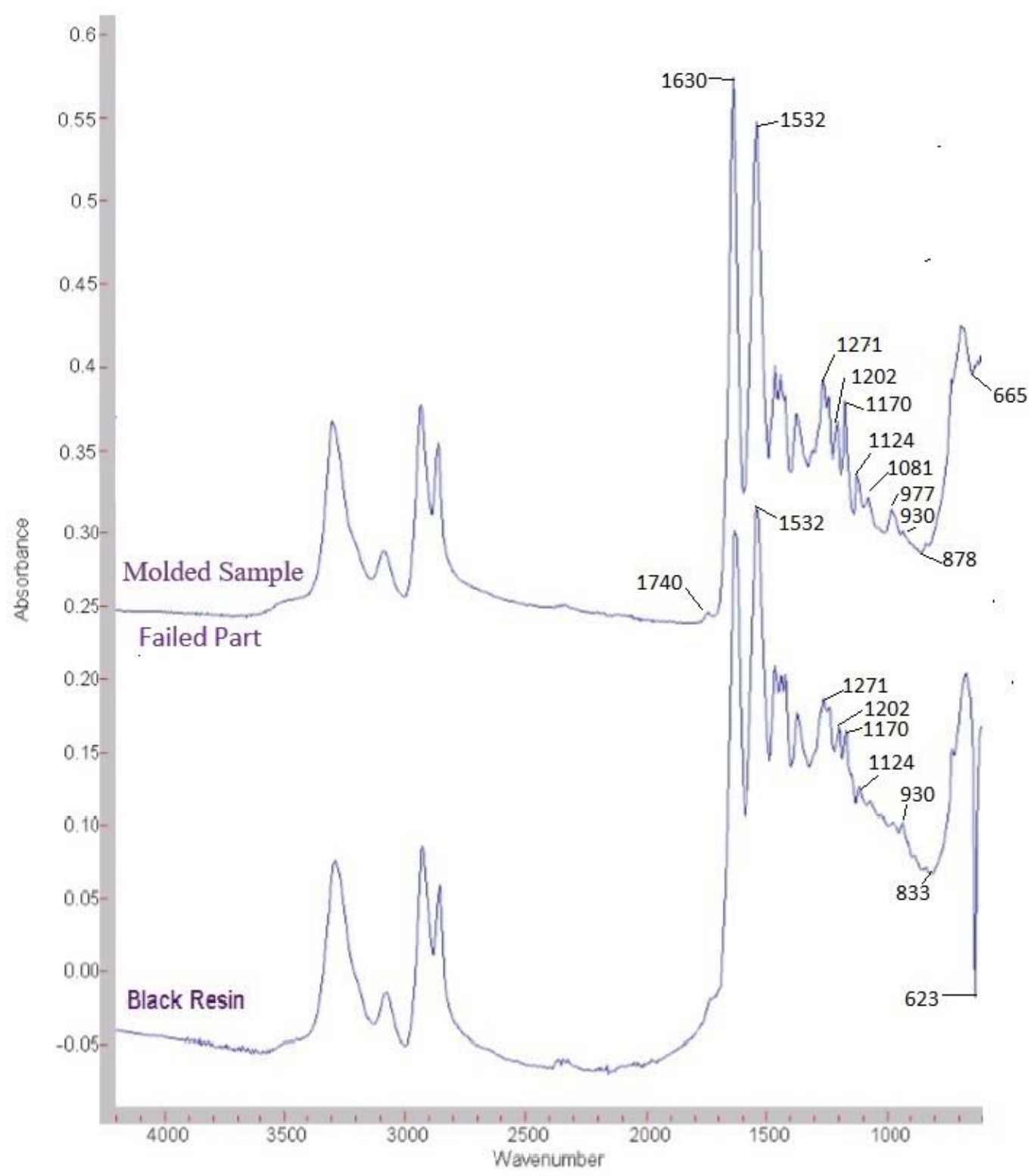

Fig. 7 - FTIR spectra of the reference sample, black resin (bottom) and the failed molded part (top).

\section{Thermogravimetric Analysis}

Thermogravimetric analysis (TGA) is a suitable tool used for examining materials' thermal behavior as well as for compositional information. The molded samples investigated were thermogravimetrically analyzed (general composition) to determine the proportions of organic (resin) and inorganic (ash) content (see the data collected in Table 2). TGA thermogram (Figure 8) shows that the sample has $0.15 \%$ of high volatile compounds, $97.34 \%$ of medium volatile compounds (resin), 1.86\% of combustible material and $0.65 \%$ of inert ash (inorganic material). At the same time, the 1st derivative profile of thermogram indicates a symmetric peak at $421^{\circ} \mathrm{C}$ which is equivalent to a single mass loss occurring at the specified temperature.

\section{Thermal Analysis}

Thermal analysis was performed by differential scanning calorimetry (DSC) in order to assess the content of crystallinity associated to the investigated samples. It is known that an increase in crystallinity degree of polymeric materials brings about enhanced mechanical and physical properties, like tensile strength, modulus of resilience, or hardness, with a direct consequence in weakening impact stress. An example of DSC thermogram as resulted on the investigated samples (see Figure 9) indicates a composition 
with a single polymer component described by a unique melting transition (peak temperature of $221.1^{\circ} \mathrm{C}$, the value consistent with that for Nylon 6 Table 3). Practically, the peak temperature at about $221^{\circ} \mathrm{C}$ is characteristic to the alpha phase and was found for each tested material.

On cooling, a crystallization peak (peak temperature of $192.0^{\circ} \mathrm{C}$ ) was detected (Figure 9). Based on the melting endotherm, the percentage of material crystallinity could be evaluated in accordance to:

$$
\mathrm{W}_{\mathrm{c}}=\left(\Delta \mathrm{H}_{\mathrm{f}} / \Delta \mathrm{H} 100\right) \times 100 \%
$$

where: $\Delta \mathrm{H}_{\mathrm{f}}-$ the measured enthalpy of the sample's melting; $\Delta \mathrm{H} 100$ - the enthalpy of a $100 \%$ pure crystalline sample's melting. In this respect, a roughly value of $230 \mathrm{~J} / \mathrm{g}$ is commonly accepted for Delta100 of PA6 at $260^{\circ} \mathrm{C}$. $^{28}$

In equation (1), on the other hand, the quantity $\Delta \mathrm{H} 100$ was considered to be $230 \mathrm{~J} / \mathrm{g}$ irrespective of temperature. ${ }^{28}$

$$
\Delta \mathrm{H}_{\mathrm{f}}(\mathrm{PA} 6)=45.7+0.74 \mathrm{~T}_{\mathrm{c}}-0.0011 \mathrm{~T}_{\mathrm{c}}^{2} \mathrm{~J} / \mathrm{g} \text {, with } \mathrm{T} \text { in }{ }^{\circ} \mathrm{C} \text {. }
$$

\section{Table 2}

Thermogravimetric Analysis - results

\begin{tabular}{l|l}
\hline Apparatus & TGA Q500 \\
\hline Temperature Range & Ambient to $1000^{\circ} \mathrm{C}$ at $50 \mathrm{C} / \mathrm{min}$ \\
Purge Gas & Ambient to $600^{\circ} \mathrm{C}-$ Nitrogen 5.0 Grade 600 to $1000^{\circ} \mathrm{C}$ - Air Zero Grade 0.1 Flow - \\
& $50 \mathrm{~mL} / \mathrm{min}$ \\
Determinations & Single \\
Component & Molded Sample with "bigger hole" \\
Highly Volatile $\left(\right.$ Ambient to $\left.150^{\circ} \mathrm{C}\right)$ & $0.15 \%$ \\
Medium Volatile $\left(150^{\circ} \mathrm{C}\right.$ to $\left.550^{\circ} \mathrm{C}\right)$ & $97.34 \%$ \\
Combustible $\left(550^{\circ} \mathrm{C}\right.$ to $\left.750^{\circ} \mathrm{C}\right)$ & $1.86 \%$ \\
Ash $\left(750^{\circ} \mathrm{C}\right.$ to $\left.1000^{\circ} \mathrm{C}\right)$ & $0.65 \%$ \\
\hline
\end{tabular}

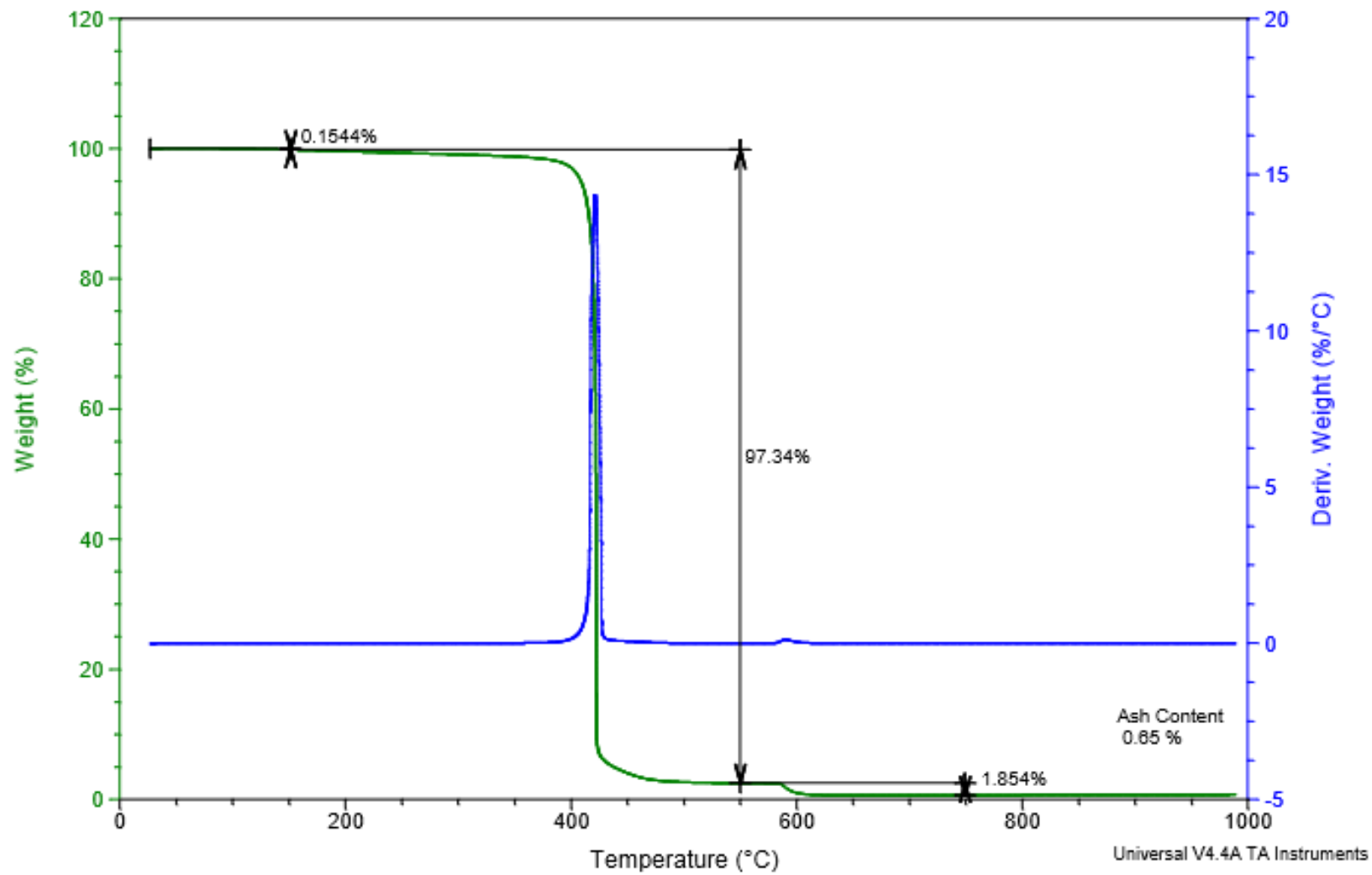

Fig. 8 - TGA thermogram (green) and its 1st derivative (blue) for an investigated sample. 


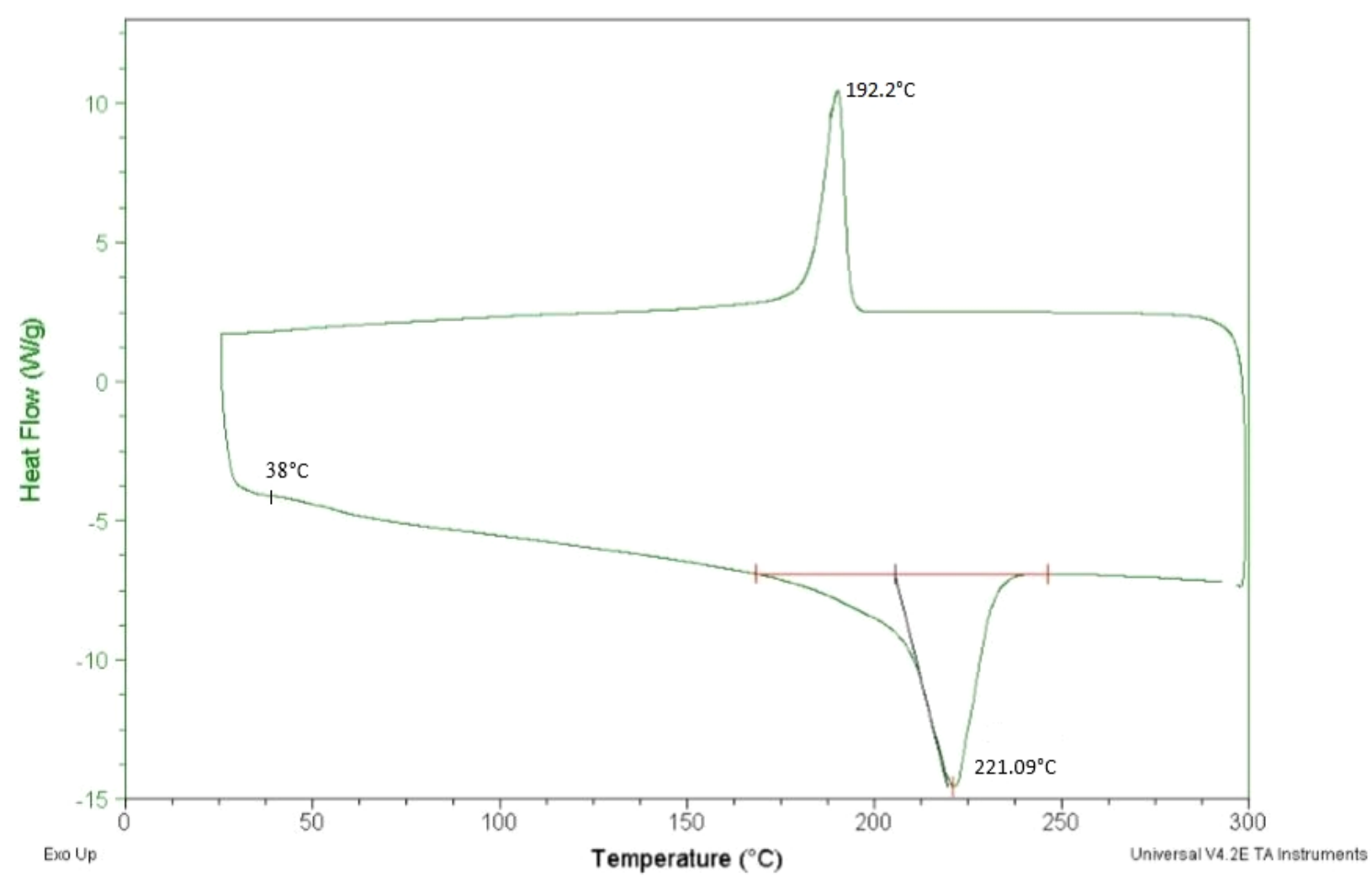

Fig. 9 - DSC thermogram for an investigated sample.

Table 3

Thermal Analysis - result

\begin{tabular}{l|c|c}
\hline Specimen & Melting Point, $\mathbf{T}_{\mathbf{m}}$ & Crystallization Temperature, $\mathbf{T}_{\mathbf{c}}$ \\
\hline Black Resin from Cracked Area & $221.09^{\circ} \mathrm{C}$ & $192.2^{\circ} \mathrm{C}$ \\
Black Resin from Good Area & $222.42^{\circ} \mathrm{C}$ & $193.3^{\circ} \mathrm{C}$ \\
\hline
\end{tabular}

According to C. Millot et al. PA6, during the heating scan of the DSC analysis, cold crystallization may take place at temperature, $\mathrm{Tc}$, between $\mathrm{Tg}$ - glass transition temperature and $\mathrm{Tm}$ - melt temperature with approximatively $20{ }^{\circ} \mathrm{C}$ above $\mathrm{Tg}$.

For

$$
\begin{gathered}
\mathrm{Tc}=58{ }^{\circ} \mathrm{C}, \Delta \mathrm{H}_{\mathrm{f}}(\mathrm{PA} 6)=45.7+0.7458-0.001158^{2}=84.92 \mathrm{~J} / \mathrm{g} \\
\mathrm{W}_{\mathrm{c}}=\left(\Delta \mathrm{H}_{\mathrm{f}} / \Delta \mathrm{H} 100\right) \times 100 \%=(84.92 / 230) \times 100 \%=36.92 \%
\end{gathered}
$$

The data of crystallinity did not suggest any material defect that could cause the cracking of the part. Instead, potential causes of structural failure could originate in manufacturing process and applied procedures. Experimental stress is one of the most versatile methods used for parts failure analysis, such as for crack failure. Consequently, flexural, Izod impact test and torque testing were performed.

\section{Flexural Properties}

Flexural testing is used to determine the flex or bending properties of a material. It measures the flexural strength and flexural modulus of a material. Similar to tensile properties, flexural properties exhibit dependence on temperature and water absorption. The specimens for flexural testing were prepared in accordance with SR EN ISO 178:2011 procedure (Table 4). Samples from two shipments were tested at room temperature. The material was submitted as molded part, and the test specimens were prepared by milling. However, the specimens were tested with the asreceived thickness. The specimens were conditioned at $23 \pm 2{ }^{\circ} \mathrm{C}$ and $50 \pm 5 \% \mathrm{RH}$ for a minimum of 40 hours prior to testing. 
Table 4

Flexural Test - Test Parameters (EN ISO 178:2010)

\begin{tabular}{l|l}
\hline Direction of Specimen Cutting: Parallel to long axis of molded part & Support Span Length: $36.58 \mathrm{~mm}$ \\
\hline $\begin{array}{l}\text { Nominal Specimen size: } 12.7 \mathrm{~mm} \text { wide x thickness of molded part x } \\
133.35 \mathrm{~mm} \text { long }\end{array}$ & Radius of Supports: $5 \mathrm{~mm}$ \\
\hline $\begin{array}{l}\text { Direction of Specimen Loading: Flatwise (load applied so convex } \\
\text { surface is in tension) }\end{array}$ & Radius of Loading Nose: $5 \mathrm{~mm}$ \\
\hline Support Span to Depth Ratio: $16: 1$ & Rate of Crosshead Motion: $0.97 \mathrm{~mm} / \mathrm{minute}$ \\
\hline
\end{tabular}

Table 5

Flexural Test - results

\begin{tabular}{c|c|c|c|c}
\hline Specimen\# & $\begin{array}{c}\text { Width } \\
(\mathbf{m m})\end{array}$ & $\begin{array}{c}\text { Depth } \\
(\mathbf{m m})\end{array}$ & $\begin{array}{c}\text { Flexural Tangent } \\
\text { Modulus (MPa) }\end{array}$ & Observations \\
\hline 1 & 12.8 & 2.27 & 1868.49 & Samples from second shipment \\
2 & 12.85 & 2.31 & 1792.64 & \\
\hline 1 & 12.8 & Average & 1830.56 & Samples from first shipment \\
2 & 12.7 & 2.32 & 1344.42 & \\
\hline
\end{tabular}

Flexural strength is described by the equation:

$$
\sigma_{b}=\frac{3 P_{\max } L}{2 b d^{2}}
$$

where: $\sigma_{\max }-$ the flexural strength, $\mathrm{P}_{\max }-$ the maximum load, $\mathrm{L}$ - the length of the support span, $\mathrm{d}$ - the thickness of the specimen, and $\mathrm{b}$ - the width of the specimen.

According to technical literature, ${ }^{29}$ the flexural modulus for extruded Nylon 6 should be $1750 \mathrm{MPa}$. The tested samples (Table 5) exhibited a large range of flexural modulus values, from ductile to brittle state. Some of flexure testing results are under $1750 \mathrm{MPa}$, which means that a lot of parts were found to be harder than the ones from normal production. It happened because of the cooling system issue of injection molding machine the mold was not heated uniformly due to a restriction in the water flow system.

\section{Notched Izod Impact Test}

Since the crack failure has developed while the molded part was merged to the mounting pin
(Figure 2), an impact test was also performed. Impact testing is used to determine material behavior at higher deformation speeds. The impact test specimens' preparation was done in accordance with ISO 2818-1996, Plastics preparation of test specimens by machining. The prepared specimens were subjected to Izod impact testing in accordance with SR EN ISO 180-2001, Method A, using a $2.71 \mathrm{Nm}$ pendulum. Two specimens of each shipment were tested at room temperature, with the as received thickness. Prior to testing, all specimens were also conditioned for a minimum of $40 \mathrm{~h}$ at $23 \pm 1{ }^{\circ} \mathrm{C}$ and $50 \pm 5 \%$ R.H.

According to technical literature, ${ }^{29}$ the impact resistance range (average) for extruded Nylon 6 is $30-250 \mathrm{~J} / \mathrm{m}(140 \mathrm{~J} / \mathrm{m})$. Izod impact test results (Table 6) also show that a lot of parts from suspect lot were found to be harder than the ones from normal production.

In completing the abovementioned mechanical investigations, density testing and durometer hardness testing were also conducted on samples from stabilized process and the average obtained results are collected in Table 7.

Table 6

Izod Impact Test - results (EN ISO 180:2000)

\begin{tabular}{|c|c|c|c|c|c|}
\hline Specimen\# & $\begin{array}{c}\text { Width along } \\
\text { Notch } \\
(\mathrm{mm}) \\
\end{array}$ & $\begin{array}{c}\text { Depth under Notch } \\
10 \pm 0.2 \\
(\mathbf{m m}) \\
\end{array}$ & $\begin{array}{c}\text { Impact Resistance } \\
(\mathrm{J} / \mathbf{m})\end{array}$ & Failure Type & Observations \\
\hline $1 \mathrm{a}$ & 2.515 & 10.16 & 82.203 & Complete Break & Samples from \\
\hline $2 \mathrm{a}$ & 2.565 & 10.16 & 56.047 & Complete Break & $\begin{array}{l}\text { second } \\
\text { shipment }\end{array}$ \\
\hline $1 b$ & 2.438 & 10.20 & 21.685 & Complete Break & Samples from \\
\hline $2 b$ & 2.413 & 10.19 & 29.845 & Complete Break & first shipment \\
\hline
\end{tabular}


Table 7

Density testing and durometer hardness testing - results, conducted on samples from stabilized process

\begin{tabular}{l|c|c}
\hline Sample\# & Density $\left(\mathbf{K g} / \mathbf{m}^{3}\right)$ & Durometer Hardness (Shore D) \\
\hline Plastic Part \#1 & $1.1210^{3}$ & 67 \\
\hline Plastic Part \#2 & $1.0710^{3}$ & 66 \\
\hline Nylon 6 Range (Average) - Density & $1.00-1.24(1.09) 10^{3}$ & - \\
\hline Nylon 6 Range (Average) - Hardness & - & $45-85(66.9)$ \\
\hline
\end{tabular}

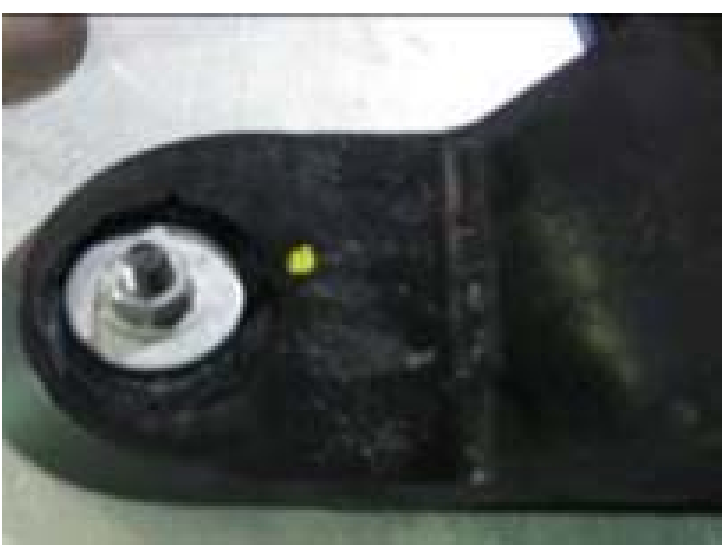

a)

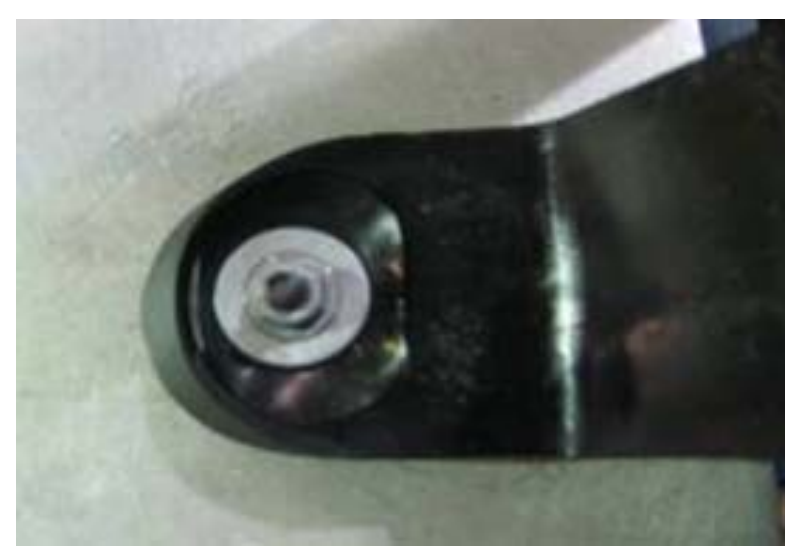

b)

Fig. 10 - Parts after torque test: a) broken bracket; b) good bracket.

\section{Torque Test to Simulate Failure}

By measuring and analyzing the torque characteristics in such applications, it is possible to accurately determine not only the quality of a part or process, but also the root cause of a wide variety of defects. A torque study, with parts from suspect lot and from stabilized production, was conducted:

(a) In the case of suspect lot, a test with a wrench of $8 \mathrm{Nm}$ torque 473 was performed using a 1000 RPM pneumatic gun. There were no broken brackets for using $3.0 \mathrm{Nm}$ torque. However, the torque study revealed that 5 of 6 parts from the suspect lot broke between 3.0 and $8 \mathrm{Nm}$. The bracket fracture surfaces has exhibited brittle characteristics (Figure 10).

As a result of overheating during molding process, polyamide thermal oxidation took place. Material oxidation is responsible for changes of polymer properties and consequently it could determine the service life of many products.

(b) From stabilized production, the tested parts were in "dry as molded" conditions. Besides the molding conditions influence over the failure of the molded parts, the parts packaging influence was also considered as a potential failure cause.
Parts from the bottom of the packed bin were also tested to see possible differences in performance between slightly warm and cold parts. This state was considered to be the worst-case scenario, because all parts were dried as much as possible.

The nut of the assembly was torqued using a calibrated torque wrench equipped with a dial which indicates the maximum torque reached. At $4 \mathrm{Nm}$ torque, a deformation of the part was observed. The part deformation continued over $8.0 \mathrm{Nm}$. All samples used for torque analysis passed the value of $8.0 \mathrm{Nm}$ imposed by customer drawing as minimum acceptable. The torque value did not increase dramatically, but it happened only after the plastic under the washer stopped deforming. In these circumstances, some samples displayed torque values that can reach $22.5 \mathrm{Nm}$ prior to overload fracturing.

The part warpage was caused due to a partial blockage of the cold-water line that cooled the die, causing a heat concentration and an inadequate cooling rate of parts, after removing from the mold. The parts got warped during their natural cooling and also due to excessive number of parts collected in container (excessive weight). 


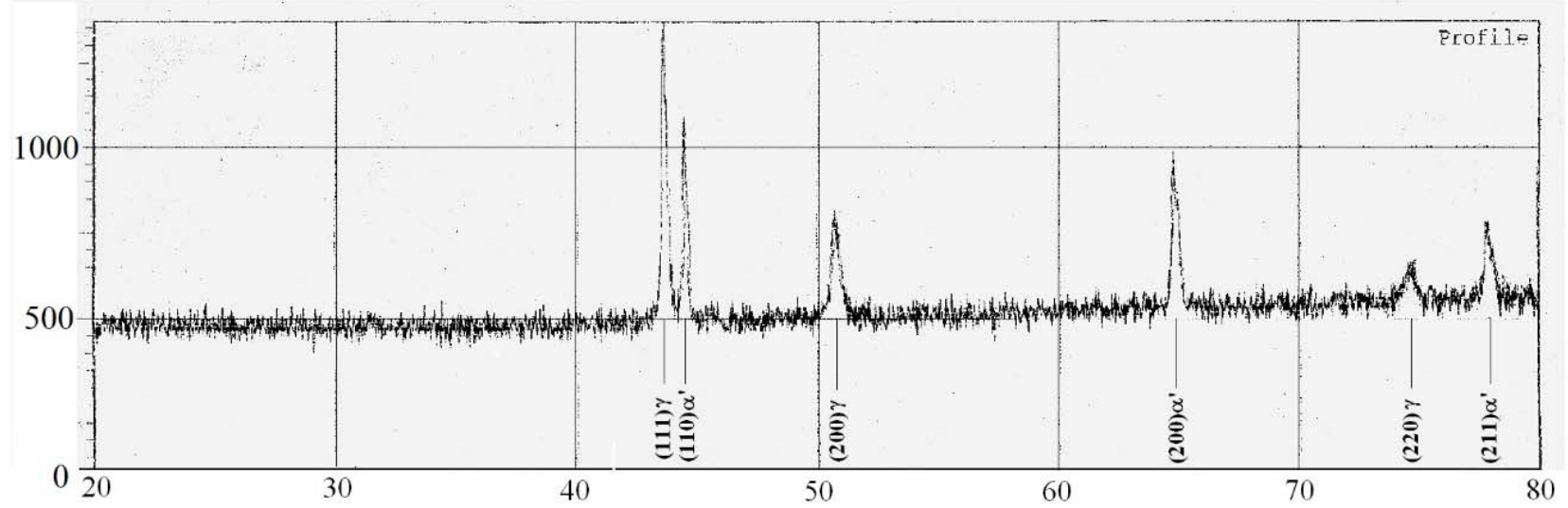

a)

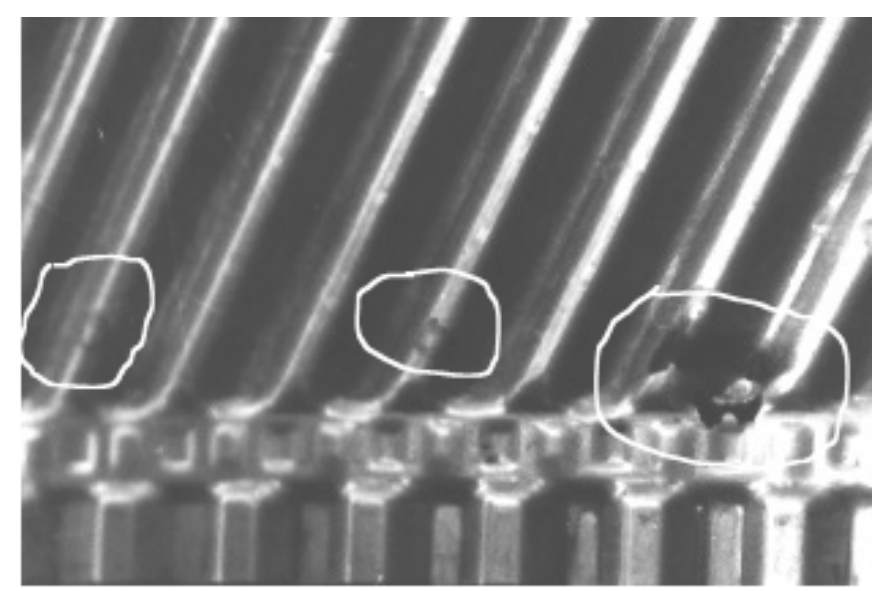

b)

Fig. 11 - Austenitic Stainless steel: a) X-ray diffraction pattern after plastic cold deformation; b) Pitting corrosion.

More likely, the susceptible parts broke down not only due to material hardening caused by cooling system blockage but also due to applied pressure at room temperature during torque test. As it was above mentioned, due to compression applied during torque test, $\gamma$ form converted into $\alpha$ form, and then this transformation was followed by material hardening, which also contributed to material failure. Similarities between austenitic stainless steel and Nylon 6 first consist in the fact that their $\gamma$ forms transform into $\alpha$ forms, as a result of either an applied heat treatment or a certain pressure applied at room temperature.

In both situations (Nylon 6; austenitic stainless steel), under an applied pressure, the material of the part became harder and then less resistant to external physical (corrosion) or mechanical action (torque test). Due to material hardening, as a result of $\gamma$ to $\alpha$ phase transition, austenitic stainless steel became less corrosion resistant ${ }^{5}$ (Figure 11) and the molded polyamide also became more brittle and susceptible to break (Figure $10 \mathrm{a}$ ).

\section{CONCLUSIONS}

Injection molding process parameters could have a strong influence on the manufactured part mechanical properties and its quality level. The mold cooling system did not work properly because the cold-water lines were found partially blocked, and it determined that the molded parts to get hotter than normal and to warp after they were naturally cooled down. The performed investigation revealed that:

The experimental findings did not show any material defect that could cause the cracking of the part. However, a lot of parts failed during mounting the mating pin. All cracks appear to have initiated at the hole where the mounting pin was inserted wherefrom and then they propagated outward. The fracture of the broken area exhibited a grainy, irregular tarring texture.

A circular indentation was noted around the mounting hole, suggesting a tightened washer/nut. This detail indicated that the part had failed due to 
over tightening during the assembly operation. The fracture had initiated at the exterior surface of the leg, near the mounting hole. This would indicate that the failure was because a one-time load exceeded the strength of the material.

Similar to austenitic stainless steel, Nylon 6 exhibited phase transformation at room temperature, gamma to alpha phase transformation. As a result, the material of molded part became harder and then less resistant to external physical (corrosion) or mechanical action (torque test).

Failed parts analysis revealed a material consistency harder (in a transition state between ductile and brittle) that of the parts from normal production (in ductile state). The torque study showed that the defective parts broke down not only due to material hardening caused by cooling system blockage, but also due to applied pressure at room temperature during torque test. It was an unusual local material hardening induced by the influence of two processes (cooling process, torque test) followed subsequently, by a failure of the molded parts.

Acknowledgments. The authors would like to acknowledge the Advanced Multifunctional Materials Laboratory (NANOMAT) of Suceava University for cooperation.

\section{REFERENCES}

1. T. B. Pala and I. J. Rao, "Creep failure analysis and shelf life determination (prevention) of injection molded parts with and without gamma irradiation", SPE ANTEC Anaheim 2017, The Plastics Technology Conference, p. 1200- 1206.

2. G. G. Trantina, "Design with Plastics, Materials Selection and Design, Volume 20, ASM Handbook, ASM International, 1997, p. $639-647$.

3. D. Wright, "Failure of Plastics and Rubber Products", 2001, Rapra Technology Limited, Revised 2006.

4. J. Kusiak, W. Libura, M. Pietrzyk and N. Solomon, Archives of Metallurgy, 1998, 43, 1998, 4-14.

5. N. Solomon and I. Solomon, U.P.B. Sci. Bull., Series B, 2010, 72, $197-206$.

6. R. F. Farias, E. L. Canedob, R. M. R. Wellen and M. S. Rabello, Materials Research., 2015, 18, 258-266.
7. B. He, Procedia Engineering, 2011, 23, 46-52.

8. M. Nikforooz, J. Montesano, M. Golzar and M. M. Shokrieh, Procedia Engineering, 2018, 213, 816-823.

9. B. A. G. Schrauwen, L. C. A. Breemen, A. B. Spoelstra, L. E. Govaert, G. W. M. Peters and H. E. H. Meijer, Macromolecules, 2004, 37, 8618-8633.

10. Y. Zhou, P. K. Mallick, Polymer Composites, 2006, 27, 230-237.

11. J. A. Jansen, Advanced Materials \& Processes, 2001, $159,56-59$.

12. S. C. Chen, H. L. Chen and P. M. Hsu, J. Reinforced Plastics and Composites, 2008, 27, 1381 - 1395.

13. F. Hamida, S. Akhbara and K.H. Ku Halim, Procedia Engineering, 2013, 68, $418-424$.

14. S. Dasgupta, W. B. Hammond and W. A. Goddard, J. Am. Chem. Soc., 1996, 118, 12291-12301.

15. C. Schick, Anal. Bioanal. Chem., 2009, 395, 1589-1611.

16. N. Vasanthan, D. R. Salem, J. Polymer Sci.: Part B: Polymer Phys., 2001, 39, 536-547.

17. E. Klata, S. Borysiak, K. Van de Velde, J. Garbarczyk and I. Krucińska, Fibres \& Textiles in Eastern Europe, 2004, $12,64-69$.

18. E. E. Kiziltas, Han-Seung Yang, A. Kiziltas, S. Boran, E. Ozen and D. J. Gardner, BioResources, 2016, 11, 4758-4769.

19. W. Steinmann, S. Walter, M. Beckers, G. Seide and T. Gries, "Thermal Analysis of Phase Transitions and Crystallization in Polymeric Fibers", Institut für Textiltechnik (ITA) der RWTH Aachen University, Aachen, Germany, Chapter 12, 2013, p. 207-306.

20. Z. Zhao, W. Zheng, H. Tian, W. Yu, D. Han and Bo Li, Mater. Lett., 2007, 61, 925-928.

21. R. Iwamoto and H. Murase, J. Polym. Sci.: Part B: Polym. Phys., 2003, 41, 1722-1729.

22. W. T. Becker, "Principles of Failure Analysis/ Ductile and Brittle Fracture", ASM International ${ }^{\circledR}$ Materials Park, OH 44073-0002, 2002.

23. S. Pashaei, M. M. Siddaramaiah, M. M. Avval and A. A. Syed, Chem. Ind. Chem. Engineering Quarterly, 2011, 17, 141-151.

24. Y. Li and W. A. Goddard, Macromolecules, 2002, 35, 8440-8455.

25. E. Parodi, G. W. M. Peters and L. E. Govaert, Polymers, 2018, $10,1-19$.

26. S. Arabnejad, S. Manzhos, AIP Advances 5, 2015, $107123,1-8$.

27. N. S. Murthy, Polym. Comm., 1991, 32, 301-305.

28. C. Millot, L. A. Fillot, O. Lame, P. Sotta and R. Seguela, J. Therm. Anal. Calorim., 2015, 122, $1-8$.

29. Normative references - Test Standards: ISO 62; ISO 75; ISO 178; ISO 179; ISO 180; ISO 294-4; ISO 527; ISO 1183, ISO 11357-1; ISO 22007-2. 
